\title{
O IMPACTO DA CULTURA SOBRE O AMBIENTE PROPÍCIO AO DESENVOLVIMENTO DE INOVAÇÕES
}

\section{Márcia Regina Santiago Scarpin}

Mestre em Administração pela Fundação Universidade Regional de Blumenau - FURB mrs.scarpin@gmail.com (Brasil)

\section{Denise Del Prá Netto Machado}

Doutor em Administração de Empresas pela Fundação Getulio Vargas - FGV

Professor da Fundação Universidade Regional de Blumenau - FURB

delpra@ furb.br (Brasil)

\section{RESUMO}

O objetivo geral deste estudo é analisar o impacto da cultura organizacional sobre o ambiente propício ao desenvolvimento de inovações em uma empresa do setor metal-mecânico. Para tanto, foi realizada uma pesquisa quantitativa descritiva, transversal. A amostra foi composta de 156 respondentes, e os dados foram analisados por meio de modelagem de equação estrutural. Como principal resultado, os empregados da empresa estudada destacaram as dimensões Resultados, Processos, Recursos, Liderança, Relacionamento Interno ao Grupo de Inovação e Efetividade de Relacionamentos como presentes no ambiente propício ao desenvolvimento de inovações. Uma cultura organizacional congruente com pequena distância do poder e alto coletivismo.

Palavras-chave: Inovação; Cultura Organizacional; Ambiente; Equação Estrutural. 


\section{INTRODUÇÃO}

Considerado fator sine qua non para a manutenção e ampliação dos negócios de uma organização, o fenômeno da inovação vem sendo estudado há anos por diversos autores, tais como Schumpeter (1911, 1982), Zaltman, Duncan e Holbeck (1973), Dosi (1982, 1988), Van de Ven e Angle (1989), Damanpour (1991), Gundling (1999), Afuah (2003), Hamel (2006), entre outros. As abordagens para este fenômeno são diversas e vão desde as macroeconômicas, advindas dos estudos schumpeterianos, até as microeconômicas, que abordam o ambiente organizacional, como os estudos de Van de Ven e Angle (1989), foco deste estudo.

A criação de um ambiente organizacional que favoreça a inovação é algo complexo. Muito além dos recursos físicos e financeiros, é necessário que as pessoas que constituem a organização internalizem essa prática no seu dia a dia, assumindo-a como um valor organizacional e encarando-a como algo necessário à sobrevivência da organização (Ahmed, 1998a; Ahmed, 1998b).

Neste sentido, a cultura organizacional pode favorecer um ambiente propício à geração de inovações por meio de uma atmosfera de encorajamento a novas ideias, pois, sendo ela um "conjunto de pressupostos básicos que um grupo inventou, descobriu ou desenvolveu [...] considerados válidos e ensinados a novos membros como a forma correta de perceber, pensar e sentir em relação a esses problemas" (Schein, 1984, p. 3), sua influência pode ser determinante na construção de uma identidade que preze a criatividade e o compromisso pelo novo. Com isso, a inovação pensada como uma ideia que, colocada em prática, gera um retorno financeiro ou econômico para a organização (Gundling, 1999), pode ser motivada por qualquer indivíduo dentro ou fora da organização.

A importância e a relevância deste estudo estão em incorporar a variável cultura organizacional nas dimensões de inovação, fornecendo variáveis ambientais que favoreçam a criação de novos produtos, processos ou serviços. Primeiro, porque a cultura organizacional é precursora dos tipos de inovação, criadas para promover a vantagem competitiva e renovação organizacional (Hogan \& Coote, 2014). Segundo, pelas características culturais da organização como distância do poder, coletivismo e aversão à incerteza influenciarem no desempenho da inovação (Mueller, Rosenbusch \& Bausch, 2013). E, finalmente, apesar da atenção dispensada para o tema cultura organizacional e inovação, a literatura existente ainda é incipiente quando se trata de uma cultura voltada para o desenvolvimento de inovações. Poucos são os estudos empíricos que promovem uma visão detalhada desta relação (Gregory et al., 2009.

Revista de Administração e Inovação, São Paulo, v.12, n.1, p.148-173, jan./mar. 2015. 
No Brasil, após pesquisa realizada nos principais periódicos nacionais (Qualis A e B) verificouse que este é um tema ainda pouco explorado, principalmente em se tratando de uma pesquisa quantitativa, já que de 198 artigos encontrados, somente dois relacionavam cultura organizacional à inovação. Martins e Terblanche (2003) afirmam que há pouco entendimento sobre quais dimensões da cultura organizacional estão relacionadas com a melhora da criatividade e da capacidade de inovar, e que poucos estudos empíricos - especialmente pesquisas quantitativas - foram realizados a fim de apoiar os resultados destes.

Diante do exposto, este artigo tem como objetivo analisar o impacto da cultura organizacional sobre o ambiente propício ao desenvolvimento de inovações em uma empresa do setor metalmecânico. Para tanto, propõe-se a seguinte questão de pesquisa: qual o impacto da cultura organizacional sobre o ambiente interno e externo ao grupo de inovação? Para responder a essa questão, este trabalho será dividido em quatro seções: na primeira, será contextualizado o desenvolvimento teórico, contemplando cultura organizacional, conceitos de inovação e relação entre cultura organizacional e ambiente propício à inovação. Na sequência, procedimentos metodológicos. Em seguida, será abordada a análise de dados e, por fim, apresentam-se as Considerações Finais.

\section{CULTURA ORGANIZACIONAL}

A cultura organizacional refere-se à forma de vida da organização (Hatch, 1997). Ela preenche as lacunas entre o que é formalmente anunciado e o que realmente acontece. É o indicador de direção que mantém a estratégia em curso, e é vista como um fator crítico de sucesso da organização (Martins \& Terblanche, 2003), podendo ainda ser definida como a cola social ou normativa que mantém uma organização unida, exprimindo os valores ou ideais sociais e as crenças que os membros da organização partilham (Smircich, 1983).

A caracterização dos elementos e níveis culturais delineia as várias formas de analisar a cultura no ambiente organizacional, formas estas denominadas "tipologias de cultura organizacional”. Bates $e t$ al. (1995) classificou a cultura organizacional em três dimensões: (a) individualismo versus coletivismo, referente às diferenças entre culturas hierárquicas e de clãs, principalmente em suas crenças sobre o papel do indivíduo frente ao papel do grupo (Ouchi, 1979); (b) distância do poder, que enfatiza a distância entre superiores e subordinados com base na autoridade formal e em símbolos de reforço do prestígio e; (c) congruência cultural, referente à homogeneidade entre os vários membros e subgrupos da organização sobre os pressupostos centrais da empresa (Saffold, 1988).

Revista de Administração e Inovação, São Paulo, v. 12, n.1, p.148-173, jan./mar. 2015. 
Epistemologicamente, Smircich (1983) sugere agrupar o tema em duas grandes perspectivas teóricas: cultura como algo que a organização "tem" estudado como uma variável organizacional, passível de ser observada de fora ou algo que a organização "é" no qual o interesse é com o deciframento da cultura, analisada pelos aspectos ideacionais e simbólicos. A cultura organizacional ainda pode ser analisada nas perspectivas racionalista, funcionalista e simbólica (Schultz, 1994).

Dependendo da questão de pesquisa, ambas as interpretações poderão ser utilizadas. Para atender o objetivo geral proposto neste estudo, optou-se por estudá-la como algo que a organização "tem", considerando-a uma variável interna da organização, contida no paradigma positivista de Burrel e Morgan (1979), ou ainda nas perspectivas racionalista e funcionalista, discutidas por Schultz (1994, p. 14). A escolha por essa abordagem ocorreu por entender-se que os gerentes atuais precisam de informações claras, objetivas e racionais para o delineamento de suas estratégias. O método quantitativo contribui para isso, pois permite analisar e encarar a cultura organizacional como um componente de gestão, passível de gerenciamento e tratamento, além de possibilitar seu estudo longitudinalmente (Aiman-Smith, 2004).

\section{INOVAÇÃO}

Mesmo sendo este um tema estudado há décadas por autores como Schumpeter $(1911,1982)$, Rogers e Shoemaker (1971), Zaltman, Duncan e Holbeck (1973), Downs e Mohr (1976), Dosi (1982, 1988), Van de Ven e Angle (1989), Damanpour (1991), Hatch (1997), Tidd, Bessant e Pavitt (1997), Gundling (1999), Afuah (2003), Hamel (2006), Ismail e Abdmajid (2007), entre outros, a literatura sobre inovação ainda é fragmentada, sendo composta por estudiosos de várias áreas, com posições ontológicas e epistemológicas distintas que buscam analisar e investigar este que é um assunto complexo e multidimensional (Wolfe, 1994; Ismail \& Abdmajid, 2007).

A inovação pode ser entendida como a adoção de uma ideia já existente, mas que é nova para a organização que a está adotando, incluindo aí novos produtos, serviços, tecnologias, processos, procedimentos, sistemas ou arranjos sociais (Rogers \& Shoemaker, 1971; Dosi, 1988; Damanpour, 1991; Afuah, 2003). Ou ainda conforme os pesquisadores do Minnesota Innovation Research Program (MIRP), a inovação pode ser considerada um processo de desenvolvimento e implantação de uma novidade (Van de Ven \& Angle, 1989).

Analisando as definições apresentadas, é possível congregá-las em um conceito como o utilizado pela empresa 3M, segundo o qual a inovação representa uma equação algébrica: ideia + ação 
= resultado financeiro ou econômico (Gundling, 1999), ou seja, algo que cria valor para o negócio da empresa.

Independentemente de sua terminologia, a inovação tem como foco principal o desenvolvimento e a exploração de um novo conhecimento, que, colocado em prática, deve ser útil, rentável e construtivo, contribuindo para o crescimento e a sobrevivência das organizações (Hall, 1984; Tidd, Bessant \& Pavitt, 1997).

\section{CULTURA ORGANIZACIONAL E AMBIENTE PROPÍCIO AO DESENVOLVIMENTO DE INOVAÇÃO}

Existem diversas razões pelas quais uma empresa não inova. Uma delas pode estar relacionada à ausência de uma cultura propícia à inovação, ou seja, à falta de capacidade da organização em desenvolver valores e práticas de gestão que promovam o desenvolvimento de novas ideias em produtos, processos ou serviços (Aiman-Smith, 2004). Sem uma gestão que desenvolva uma cultura para apoiar e guiar atividades de inovação, qualquer esforço nesta direção poderá não ter resultados positivos e esperados. Alguns estudos apontam que o sucesso de empresas altamente inovadoras está embasado em uma cultura voltada para a inovação, a qual disponibilizará recursos físicos, financeiros e humanos para apoiar e nutrir um clima de criatividade e inovação (Ahmed, 1998a; Ahmed, 1998b; Parolin \& Albuquerque, 2010).

Uma cultura inovativa, portanto, é "a habilidade da organização de adotar ou implementar novas ideias, processos ou produtos com sucesso" (Hurley \& Hult, 1998, p. 44). "Uma das características universais das empresas inovadoras é uma cultura aberta. Uma cultura que abrange as relações em todas as direções, todas as funções e departamentos internamente [...]" (Kanter et al., 1998, p. 20).

No entendimento do Minnesota Innovation Research Program (MIRP), a inovação não é um trabalho para ser executado por uma só pessoa, mas sim por uma rede de pessoas que focam o desenvolvimento de uma série de ideias e que, por meio de interações ou transações, tornam-se suficientemente comprometidas com essas ideias a fim de conseguir aceitação e legitimidade (Van de Ven \& Angle, 1989; Vick, Nagano \& Santos, 2009).

Pela estrutura do Minnesota Innovation Research Program (MIRP), a efetividade da inovação percebida é hipotetizada por ser uma função da dimensão interna de um grupo de inovação, contemplando dimensões como: (a) Resultado: grau com que as pessoas percebem que a inovação

Revista de Administração e Inovação, São Paulo, v. 12, n.1, p.148-173, jan./mar. 2015. 
atendeu suas expectativas individuais e da empresa em termos de processo e resultados; (b) Processo: são processos necessários ao desenvolvimento da inovação, compreendendo regras bem definidas e procedimentos padronizados; (c) Recursos: quantidade de recursos disponíveis para o desenvolvimento de inovações; (d) Liderança: estímulo aos indivíduos a gerarem novas ideias e aprenderem com os próprios erros; (e) Autonomia: liberdade dos funcionários em exporem suas ideias e opiniões no intuito de ajudar no processo decisório referente à inovação; (f) Relacionamento interno do grupo de inovação: refere-se ao grau de interação e consenso e forma de resolução de conflitos entre o grupo de inovação; (g) Relacionamento externo ao grupo de inovação: refere-se ao grau de interação do grupo de inovação com outros grupos dentro da empresa a fim de buscar auxílio para o desenvolvimento de inovações e benefícios mútuos; (h) Dependência de recursos externos: grau com que um grupo de inovação percebe a sua dependência de recursos (dinheiro, informação, materiais, etc.) de outros grupos da organização; (i) Formalização: grau com que os relacionamentos com outros grupos são verbalizados ou documentados; (j) Efetividade: grau com que os indivíduos percebem que o relacionamento com grupos externos vale a pena e satisfaz aos objetivos propostos (Van de Ven \& Angle, 1989).

O sucesso da inovação parece depender de dois ingredientes básicos: fontes técnicas (pessoal, equipamentos, conhecimento, dinheiro, etc.) e competências na organização para gerenciá-las. Sendo necessário um contexto organizacional favorável, com pressupostos voltados para o desafio e à ação, para a liberdade de debates e interação e à disseminação e celebração de estórias e mitos sobre o sucesso das inovações (Tidd; Bessant \& Pavitt, 1997; Ahmed, 1998a).

Para Van de Ven (1986, p. 591), “o processo de inovação é definido como o desenvolvimento e a implementação de novas ideias por pessoas que, ao longo do tempo, se envolvem em transações com outras, dentro de um contexto institucional". Sendo assim, esse ambiente pode emergir de forma não intencional, decorrente de um modelo de gestão participativa com grande abertura entre os canais de comunicação internos (Machado, 2007; Miguel \& Teixeira, 2009). Rogers (1995) já enfatiza que o processo de comunicação e a transmissão de informações é a base para a geração de novas ideias.

Com isso, é possível dizer que a inovação consiste em aprender a encontrar soluções mais apropriadas para gerenciar o processo de maneira eficaz. Requer tempo e dinheiro, afeta e perturba o trabalho rotineiro e exige comprometimento e habilidades. Ela também precisa ser pensada de forma integrada com o negócio central da organização e pelas diversas áreas que a compõem. Desta forma, um dos recursos mais significativos para otimizar seu rápido desenvolvimento é a importância atribuída às pessoas (Moch \& Morse, 1977; Sbragia, 1993; Tidd, Bessant \& Pavitt, 1997; Ahmed, 1998a, Ahmed, 1998b; Kanter et al., 1998; Gobara et al., 2010; Parolin \& Albuquerque, 2010; Vicenti

Revista de Administração e Inovação, São Paulo, v.12, n.1, p.148-173, jan./mar. 2015. 
Márcia Regina Santiago Scarpin \& Denise Del Prá Netto Machado

\& Machado, 2010). A inovação, portanto, é o principal condutor da tendência em direção a altos níveis de trabalho em equipe interfuncional e interorganizacional (Tidd, Bessant \& Pavitt, 1997).

\section{METODOLOGIA DA PESQUISA}

Considerando que o principal objetivo deste estudo é analisar o impacto da cultura organizacional sobre o ambiente propício ao desenvolvimento de inovações em uma empresa do setor metal-mecânico, foi escolhida uma pesquisa quantitativa descritiva transversal, por meio de levantamento de dados primários, com a aplicação de questionário com perguntas fechadas. Segundo Hair Jr. et al. (2005), a pesquisa quantitativa é uma investigação empírica cuja finalidade é delinear ou analisar fenômenos, avaliar programas ou isolar variáveis-chave.

A empresa Alpha foi selecionada por conveniência de forma intencional e não probabilística para constituir objeto de estudo desta pesquisa por se tratar de uma empresa do setor metal-mecânico, com 65 anos de existência, situada no alto Vale do Itajaí, com faturamento anual de aproximadamente 150 milhões de reais, sendo hoje uma das maiores fabricantes latino-americanas de peças automotivas, como guias, sedes, tuchos e mecânicos de válvula fundidos em ligas especiais. A questão acessibilidade influenciou na escolha da empresa, após serem consideradas as características básicas para o desenvolvimento da pesquisa, tais como a existência de uma cultura apoiada e sustentada por seu fundador - atuante na administração da empresa - e a existência de programas que incentivam o desenvolvimento de inovações, como o Seis Sigma.

A população total é composta por 1.200 empregados. Como todos os empregados foram considerados aptos a responder à pesquisa, os sujeitos sociais foram selecionados por conveniência, abrangendo todos os setores, ou seja, do setor administrativo ao setor produtivo. A pesquisa teve apoio total da diretoria. Primeiro foi realizada uma reunião com a responsável pelo setor de recursos humanos, onde foi apresentado o objetivo, conteúdo e finalidade da pesquisa. Também foi mostrado o questionário e dado instruções sobre a maneira correta do seu preenchimento. A partir dessa etapa, o responsável pelo RH reuniu os gerentes/supervisores de cada setor/turno para orientar sobre o motivo da pesquisa, seu conteúdo e como os questionários deveriam ser preenchidos e entregues ao grupo de funcionários. As explicações foram impressas no cabeçalho do questionário para facilitar o repasse de informação. No total foram impressos 1200 questionários e entregues 1154, pois alguns funcionários estavam de férias ou licença. Os funcionários foram informados a depositar os questionários respondidos em urna instalada no refeitório da empresa.

Revista de Administração e Inovação, São Paulo, v. 12, n.1, p.148-173, jan./mar. 2015. 
A amostra por conveniência obteve um erro amostral de 7,5\%, sendo seu grau de significância de 92,5\%, calculados com base em Barbetta (2001). A amostra total foi representada por 156 respondentes. Ressalta-se que foram recolhidos 170 questionários e inutilizados 14, pois apresentavam questões em branco, o que os invalidou. Conforme Hair Jr.et al. (2005, p. 484), “o tamanho absoluto mínimo da amostra deve ser pelo menos maior do que o número de covariância ou correlações na matriz de dados de entrada". O modelo proposto neste estudo conta com 13 dimensões e 5 ligações, totalizando 18 parâmetros. Dessa forma, a amostra se apresentou adequada ao número de parâmetros.

O modelo utilizado para esta pesquisa é formado de duas partes. A primeira refere-se ao tema inovação e é composta por vinte e oito questões. O modelo proposto se baseou na metodologia Minnesota Innovation Survey (MIS), descrita por Van de Ven e Angle (1989) para análise do ambiente de inovação. Machado e Carvalho (2013) analisaram os construtos teóricos e observaram a possibilidade de agrupamento das dimensões que, por meio de análise fatorial, se mostraram factíveis devido à multicolinearidade entre os dados. Com isso, as 29 dimensões propostas por Van de Ven e Angle (1989), foram reduzidas para 10, agrupadas da seguinte maneira:

(a) Dimensões Internas ao Grupo de Inovação: (D2) processos, (D3) recursos, (D4) liderança, (D5) autonomia, (D6) relacionamento interno do grupo de inovação, (D7) relacionamento externo ao grupo de inovação.

(b) Dimensões Externas ao Grupo de Inovação, mas interna à empresa: (D8) dependência de recursos externos, (D9) formalização, (D10) efetividade do relacionamento.

(c) Resultado: (D1) resultados.

A metodologia do Minnesota Innovation Survey (MIS) pode ser observada nos estudos de Kannan-Narasimhan (2014), nos quais demonstrou que o ganho de recursos pode gerar legitimidade às inovações em estágio inicial. Goh, Goodman e Weingart (2013) que analisaram os ciclos de validação da inovação, nos quais as equipes de inovação alinham a sua produção com os requisitos do projeto por meio de modificações incrementais. E, também nos estudos de Börjesson e Elmquist (2011) 'que realizaram um estudo longitudinal na empresa Volvo e verificaram que uma empresa inovadora precisa desenvolver constantemente suas competências gerenciais que propiciem um ambiente favorável à criação.

A segunda parte do modelo de ambiente propício ao desenvolvimento de inovações acrescentou o construto "cultura organizacional", utilizando para isso o questionário adaptado de Bates et al. (1995), que apresenta três dimensões referentes à tipologia da cultura organizacional, sendo elas (1) individualismo versus coletivismo, (2) distância do poder e (3) congruência cultural. É importante 
observar que as duas primeiras dimensões possuem o mesmo nome empregado nos estudos de Hofstede (1980), porém com aplicações distintas, visto que o autor conduziu um estudo voltado para a cultura das nações, enquanto Bates et al. (1995) utilizaram-nas para a análise da cultura interna da organização, com a finalidade de comparar comportamentos de grupos, referenciando as bases teóricas de Georgopoulos e Mann (1962), Aiken e Hage (1966), Taylor e Bowers (1972) e Ouchi (1979, 1982).

Referenciando Bates et al. (1995) os estudos de Moran e Meso (2008) relacionaram cultura organizacional com a capacidade de aprendizagem da empresa. Naor, Linderman e Schroeder (2010) reforçou a cultura organizacional como fonte para desempenho superior da firma e, Yang e Yang (2012) demonstrou que uma cultura organizacional adequada auxilia a formação de uma estratégia voltada para a flexibilidade.

A partir de Machado e Carvalho (2013) e Bates et al., (1995), o instrumento de coleta foi composto por perguntas sobre inovação e cultura organizacional. As vinte e oito perguntas referentes à inovação, devidamente validadas para o contexto brasileiro, foram as propostas por Machado e Carvalho (2013). As dezessete perguntas sobre cultura organizacional foram traduzidas do modelo original de Bates et al., (1995), esse segundo processo passou por tradução reversa à análise do vocabulário brasileiro. Observa-se que formam utilizadas somente perguntas referentes à cultura organizacional. As perguntas voltadas para a estratégia de operações ou, as específicas para o chão de fábrica foram retiradas da análise.

O questionário completo, formado pelas escalas originais de Machado e Carvalho (2013) e Bates et al., (1995) passou pelo método $Q$-sort (Howard, 1998). Um grupo de doze acadêmicos e cinco gerentes industriais receberam um conjunto de 45 perguntas e 13 dimensões, alocando cada pergunta a uma dimensão específica. O resultado foi satisfatório e as dimensões confirmadas. Neste processo, alguns ajustes de vocabulário foram realizados para melhor adequar o questionário ao público respondente. A partir deste refinamento, foi realizado um pré-teste com 41 respondentes o qual apresentou bons índices de confiabilidade.

Com isso, foi possível propor o modelo conceitual apresentado na Figura 1, englobando aspectos de cultura organizacional e ambiente propício ao desenvolvimento de inovação, utilizando os construtos advindos das relações do grupo de inovação (Machado, Carvalho \& Heinzmann, 2012). A estrutura do modelo consiste no pressuposto de que o processo de inovação incide na motivação e coordenação de pessoas para desenvolver e implementar ideias (Van de Ven \& Angle, 1989).

Ressalta-se que os construtos Dimensões Internas e Externas à inovação referem-se ao grupo de inovação interno da empresa, e que o construto cultura organizacional refere-se às características destes grupos.

Revista de Administração e Inovação, São Paulo, v. 12, n.1, p.148-173, jan./mar. 2015. 


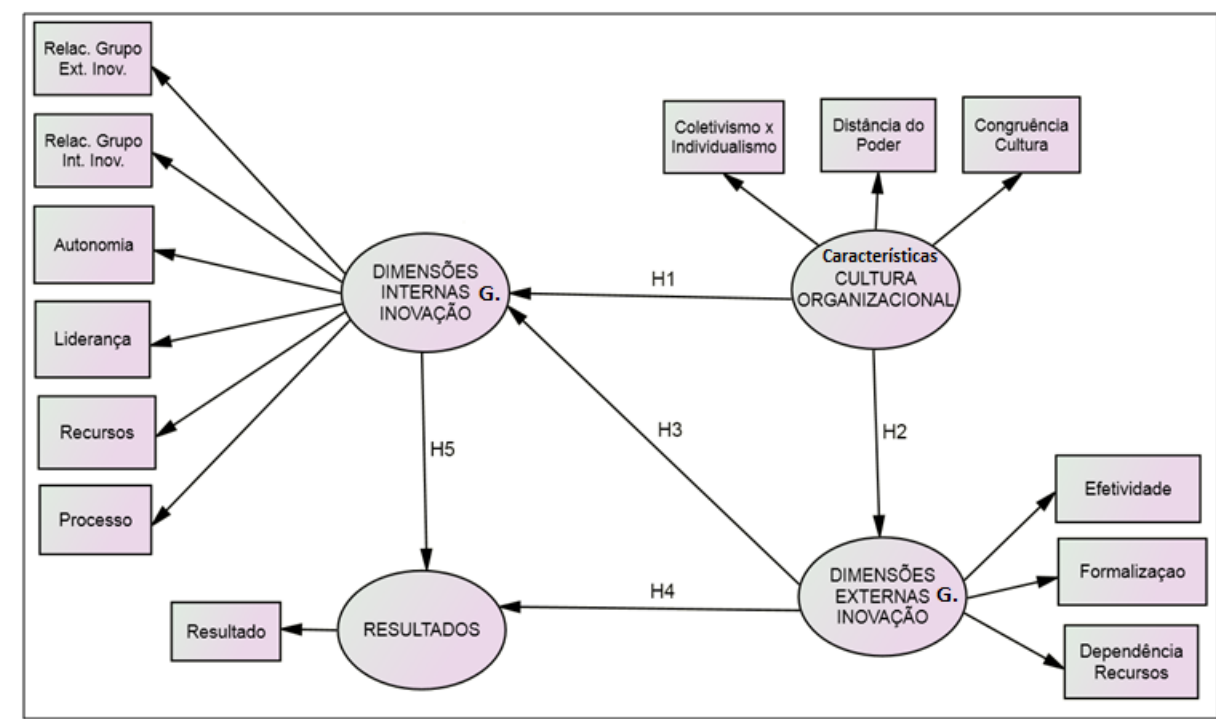

Figura 1 - Modelo englobando cultura organizacional e ambiente propício ao desenvolvimento de inovações

Fonte: Adaptado de Van de Ven e Angle (1989) e Bates et al. (1995)

Considerando o modelo apresentado, espera-se confirmar as seguintes hipóteses:

a) H1: A Cultura Organizacional impacta as Dimensões Internas do grupo de Inovação.

b) H2: A Cultura Organizacional impacta as Dimensões Externas ao grupo de Inovação.

c) H3: A Cultura Organizacional composta pelas Dimensões Externas ao grupo de Inovação impacta as Dimensões Internas do grupo de Inovação.

d) H4: A Cultura Organizacional composta pelas Dimensões Externas ao grupo de Inovação impacta os Resultados.

e) H5: A Cultura Organizacional composta pelas Dimensões Internas e Externas ao grupo de Inovação impacta os Resultados.

Para averiguar as hipóteses apresentadas, foram caracterizadas as dimensões que representavam o ambiente propício ao desenvolvimento de inovações. Para tanto, selecionaram-se as dimensões percebidas positivamente pelos empregados por meio da análise de frequência com valores superiores a 50\%, aliada ao resultado do alfa de Cronbach com valores acima de 0,60 que conforme Hair Jr. et al. (2005) é um nível recomendado, e que quanto mais próximo de 1, maior a sua confiabilidade. Para esta primeira etapa foi utilizado o software estatístico SPSS (Statistical Package for the Social Sciences) versão 19.

Na segunda etapa, utilizou-se a técnica de modelagem de equações estruturais (MEE), que é uma metodologia estatística com abordagem confirmatória na análise da estrutura teórica sobre um 
determinado fenômeno, fornecendo ao pesquisador a habilidade de acomodar múltiplas relações de dependência inter-relacionadas em um só modelo (Bentler, 1988).

Para Anderson e Gerbing (1998), o modelo híbrido deve ser avaliado em dois momentos: o primeiro envolve a construção de um modelo de mensuração aceitável por meio de uma Análise Fatorial Confirmatória, determinando o modelo de mensuração. Neste estudo, esta etapa foi realizada na construção do modelo; dessa forma, o que se pretende aqui é executar o segundo momento, que consiste em avaliar as relações entre os construtos, determinadas pelo conjunto de regressões que compõem o modelo estrutural, confirmando sua aderência.

Portanto, partiu-se do modelo originalmente proposto para se obter os índices de ajuste iniciais e garantir sua representatividade junto ao conjunto inteiro de relações causais, com medidas de ajuste absoluto e incremental, por meio da representação pictórica, também chamada de diagrama de caminhos, com setas retilíneas indicando uma relação causal direta de um construto a outro (Hair et al., 2005). Para esse procedimento, o software estatístico utilizado foi o SPSS AMOS 18.0, que permite gerar as equações de correlação entre as dimensões, demonstrando graficamente o valor de impacto e os valores para a explicação do modelo (R2), esperando assim ser avaliado o impacto da cultura organizacional sobre o ambiente propício para a inovação.

\section{RESULTADO DA PESQUISA}

Com objetivo de analisar o impacto da cultura organizacional sobre o ambiente propício ao desenvolvimento de inovações em uma empresa do setor metal-mecânico, na primeira etapa, foram avaliadas as características dos entrevistados.

Tabela 1 - Caracterização dos entrevistados

\begin{tabular}{|l|c|c|}
\hline Dados & Amostra & Universo \\
\hline A idade média dos entrevistados & 30,38 anos & 31 anos \\
\hline $\begin{array}{l}\text { Escolaridade: } \\
\text { a) Nível primário }\end{array}$ & $4,5 \%$ & $15,94 \%$ \\
\hline b) $1^{\circ} \mathrm{Grau}$ & $10,9 \%$ & $22,38 \%$ \\
\hline c) $2^{\circ} \mathrm{Grau}$ & $54,5 \%$ & $52,42 \%$ \\
\hline G) Praduados & $18,6 \%$ & $4,93 \%$ \\
\hline e) & $11,5 \%$ & $4,33 \%$ \\
\hline $\begin{array}{l}\text { Setor: } \\
\text { a) Administrativo, contemplando setores como: } \\
\text { financeiro, marketing, RH, planejamento e controle de } \\
\text { qualidade, entre outros. }\end{array}$ & $27,25 \%$ & $5,91 \%$ \\
\hline $\begin{array}{l}\text { b) Produção, o qual abrangeu setores como usinagem, } \\
\text { moldagem, expedição, engenharia da produção, guias, fusão, }\end{array}$ & $72,75 \%$ & $94,09 \%$ \\
\hline
\end{tabular}

Revista de Administração e Inovação, São Paulo, v. 12, n.1, p.148-173, jan./mar. 2015. 
acabamento, fundição, suprimentos, suporte, sedes, camisas, tuchos e almoxarifado, entre outros constantes em uma tabela completa no apêndice

O tempo médio de trabalho dos empregados na empresa

\begin{tabular}{|c|c|}
\hline 6 anos & $\begin{array}{c}6 \text { anos e 1 } \\
\text { mês }\end{array}$ \\
\hline
\end{tabular}

Conforme apresentado na Tabela 1, é possível perceber que na amostra coletada a idade média dos funcionários da empresa é de 30 anos e o nível de escolaridade predominante é o $2^{\circ}$ grau, com $54 \%$. Além disso, a amostra conseguiu abranger $27 \%$ do setor administrativo e $72 \%$ do setor de produção. E finalmente, observou-se que a idade média de trabalho dos empregados é de 6 anos.

Pela comparação entre a amostra e o universo da pesquisa, verifica-se que os dados podem ser considerados representativos, pois os elementos contidos em cada extrato não estão distantes do universo pesquisado, demonstrando baixa variância (Anderson et al., 2011).

\subsection{Confiabilidade das dimensões}

Após analisar as frequências das variáveis de inovação e cultura organizacional, foi possível identificar quais delas eram percebidas pelos empregados da empresa pesquisada. Com isso, para representar um ambiente propício ao desenvolvimento de inovações, foram selecionadas as dimensões percebidas positivamente aliadas ao indicador de confiabilidade das respostas obtido por meio do alfa de Cronbach*, com valor > 0,60 (Hair Jr. et al. 2005).

Dessa forma, a partir da percepção dos respondentes e da confiabilidade dos dados foram selecionadas as dimensões D1 - Resultados $\left(0,86^{*}\right)$, D2 - Processos $\left(0,66^{*}\right)$, D3 - Recursos $\left(0,86^{*}\right)$, D4 - Liderança $(0,60 *)$, D6 - Relacionamento Interno com o Grupo de Inovação (0,67*), D10 Efetividade do Relacionamento $\left(0,68^{*}\right)$, D11 - Coletivismo $\left(0,85^{*}\right)$, D12 - Pequena Distância do Poder $\left(0,70^{*}\right)$ e D13 - Congruência Cultural $\left(0.88^{*}\right)$, para entender as relações causais por meio da modelagem de equações estruturais.

Observa-se que as dimensões D5 - Autonomia (0,40), D7 - Relacionamento externo ao grupo de inovação $(0,47)$, D8 - Dependência de recursos externos $(0,27)$ e D9 - Formalização $(0,35)$, foram retiradas da análise de modelagem de equações estruturais, por demonstrarem baixos níveis de confiabilidade.

Com a retirada das dimensões D8 e D9, o construto 'Dimensões Externas ao grupo de Inovação' ficou somente com a dimensão D10 - Efetividade do Relacionamento. Esse fato fez com que os itens da dimensão, compostos por parceria, comprometimento e adaptabilidade, fossem utilizados na análise da modelagem, seguindo as orientações de Hair Jr., et al. (2005).

Revista de Administração e Inovação, São Paulo, v.12, n.1, p.148-173, jan./mar. 2015. 


\subsection{Medidas de qualidade/confiabilidade do ajuste geral do modelo}

A partir da adequação no modelo original, medidas de ajuste absoluto foram empregadas nas dimensões selecionadas, tais como Qui-quadrado da razão de verossimilhança $(\chi 2)$ e a raiz do resíduo quadrático médio, com a finalidade de certificar a representação adequada do conjunto inteiro de relações causais, apresentados na Tabela 2.

Tabela 2 - Estatística qui-quadrado

\begin{tabular}{|c|c|}
\hline Chi-square $=$ & 120,842 \\
\hline Degrees of freedom $=$ & 60 \\
\hline Probability level &, 000 \\
\hline$\chi^{2} / \mathrm{GL}$ & 2,0140 \\
\hline
\end{tabular}

O valor do Qui-quadrado de 120,852, com 60 graus de liberdade, é estatisticamente significante no nível de 0,000. O que se busca é um valor de Qui-quadrado não significativo, dado que H0 indica que os dados se ajustam ao modelo. No caso do valor ser significativo, alguns autores defendem que se possa dividir o seu valor pelos graus de liberdade ( $\left.\chi^{2} / \mathrm{GL}\right)$. Para Kline (1998), uma razão menor do que três é aceitável e para Hair Jr. et al. (2005) esse valor deve ser igual ou inferior a cinco. Porém, como a sensibilidade dessa medida não é excessivamente afetada pelo tamanho da amostra de 156 respondentes, pode-se concluir que existem diferenças significantes. No entanto, o teste Qui-quadrado é sensível a não normalidade dos dados, ao número de parâmetros e ao tamanho da amostra, recomendando-se que este índice seja analisado em conjunto com outros indicadores (Hair Jr. et al. 2005).

Complementando o Qui-quadrado, foi realizada a raiz do erro quadrático de aproximação (RMSEA), que resultou em um valor de 0,055, representando qualidade no ajuste do modelo, visto que os valores recomendados variam entre 0,05 a 0,08 (Hair Jr. et al., 2005).

Essas medidas de ajuste absoluto indicam que o modelo é aceitável, porém outras medidas de ajuste fornecerão diferentes perspectivas sobre a aceitabilidade, como é o caso das medidas de ajuste incremental, que comparam o modelo proposto com um modelo nulo, que é formado apenas por um fator e sem erro de mensuração. Pela Tabela 3 é possível verificar os indicadores que representam tais medidas. 


\section{Tabela 3 - Medidas de Ajuste incremental}

\begin{tabular}{|c|c|c|}
\hline Tipo de medida & Valor modelo & Valor de referência \\
\hline Normed Fit Index (NFI) &, 901 &, 90 \\
\hline $\begin{array}{c}\text { Tucker-Lewis Index ou Non-Normed Fit Index } \\
\text { (NNFI) }\end{array}$ &, 919 &, 90 \\
\hline Comparative Fit Index (CFI) &, 946 &, 90 \\
\hline
\end{tabular}

Além destas, existem outras medidas de ajuste, porém foram selecionadas as principais, como forma de demonstrar que os níveis de qualidade de ajustes estão adequados, com valores acima de 0,90 (Hair Jr. et al., 2005).

De acordo com Hair et al. (2005), após o ajuste geral do modelo ter sido avaliado, pode-se, ainda, examinar cada construto quanto à unidimensionalidade, que se refere ao grau em que um conjunto de itens representa apenas um construto. Para isso, foi realizada a validade discriminante, formando-se todos os pares possíveis dos construtos, conforme apresentado na Tabela 4.

Tabela 4 - Validade Discriminante entre construtos

\begin{tabular}{|l|c|c|}
\hline Construtos & $\begin{array}{c}\text { Cálculo do valor } \\
\text { da diferença do } \\
\text { Qui-quadrado }\end{array}$ & Resultado \\
\hline $\begin{array}{l}\text { Dimensões Internas ao Grupo de Inovação versus Cultura } \\
\text { Organizacional }\end{array}$ & 10,057 & Diferentes \\
\hline $\begin{array}{l}\text { Dimensões Int. ao G. de Inovação versus Dimensões Ext. ao G. } \\
\text { Inovação }\end{array}$ & 05,281 & Diferentes \\
\hline Dimensões Internas ao Grupo de Inovação versus Resultado & 16,006 & Diferentes \\
\hline $\begin{array}{l}\text { Cultura Organizacional versus Dimensões Externas ao Grupo } \\
\text { de Inovação }\end{array}$ & 55,036 & Diferentes \\
\hline Cultura Organizacional versus Resultado & 183,295 & Diferentes \\
\hline Dimensões Externas ao Grupo de Inovação versus Resultado & 62,584 & Diferentes \\
\hline
\end{tabular}

Um valor significativo para a diferença da estatística qui-quadrado para os dois modelos alinhados indica que os construtos são diferentes e garante a validade discriminante (O'leary-Kelly \& Vokurka, 1998). Todos os pares de construtos apresentaram uma diferença na estatística qui-quadrado significativa $(\mathrm{p}<0,05)$.

\subsection{Diagrama do modelo do impacto da cultura organizacional sobre o ambiente propício ao desenvolvimento de inovação}

Os diagramas são a base para a análise de caminhos, os quais calculam a força das relações usando apenas uma matriz de correlação ou covariância como entrada. A correlação simples 
(bivariada) entre duas variáveis quaisquer pode ser representada como a soma dos caminhos compostos conectando esses pontos (Hair et al., 2005).

Para analisar o impacto da cultura organizacional sobre o ambiente propício ao desenvolvimento de inovação foi realizada a modelagem de equações estruturais (MEE). Como forma de verificar esse impacto, foram simuladas duas matrizes alternativas: a primeira contempla todas as dimensões propostas no modelo, sendo elas: Cultura Organizacional, Dimensões Internas ao Grupo de Inovação, Dimensões Externas ao Grupo de Inovação e Resultado, o qual será analisado conforme as hipóteses propostas, por meio da Figura 2; a segunda considera somente o ambiente propício ao desenvolvimento de inovações, excluindo o construto Cultura Organizacional, para comparação dos resultados. Esta última matriz tem como finalidade somente demonstrar o impacto e não analisar o modelo em si.

Os coeficientes foram padronizados a um valor máximo de 1,0, sendo que valores próximos a zero têm pouco ou nenhum efeito substantivo e, conforme esse valor aumenta, sua importância intensifica as relações causais (Hair Jr. et al., 2005).

Os resultados serão apresentados conforme hipóteses elaboradas. Cada figura associará a variável exógena Cultura Organizacional a um construto, indicando os parâmetros estimados para o modelo.

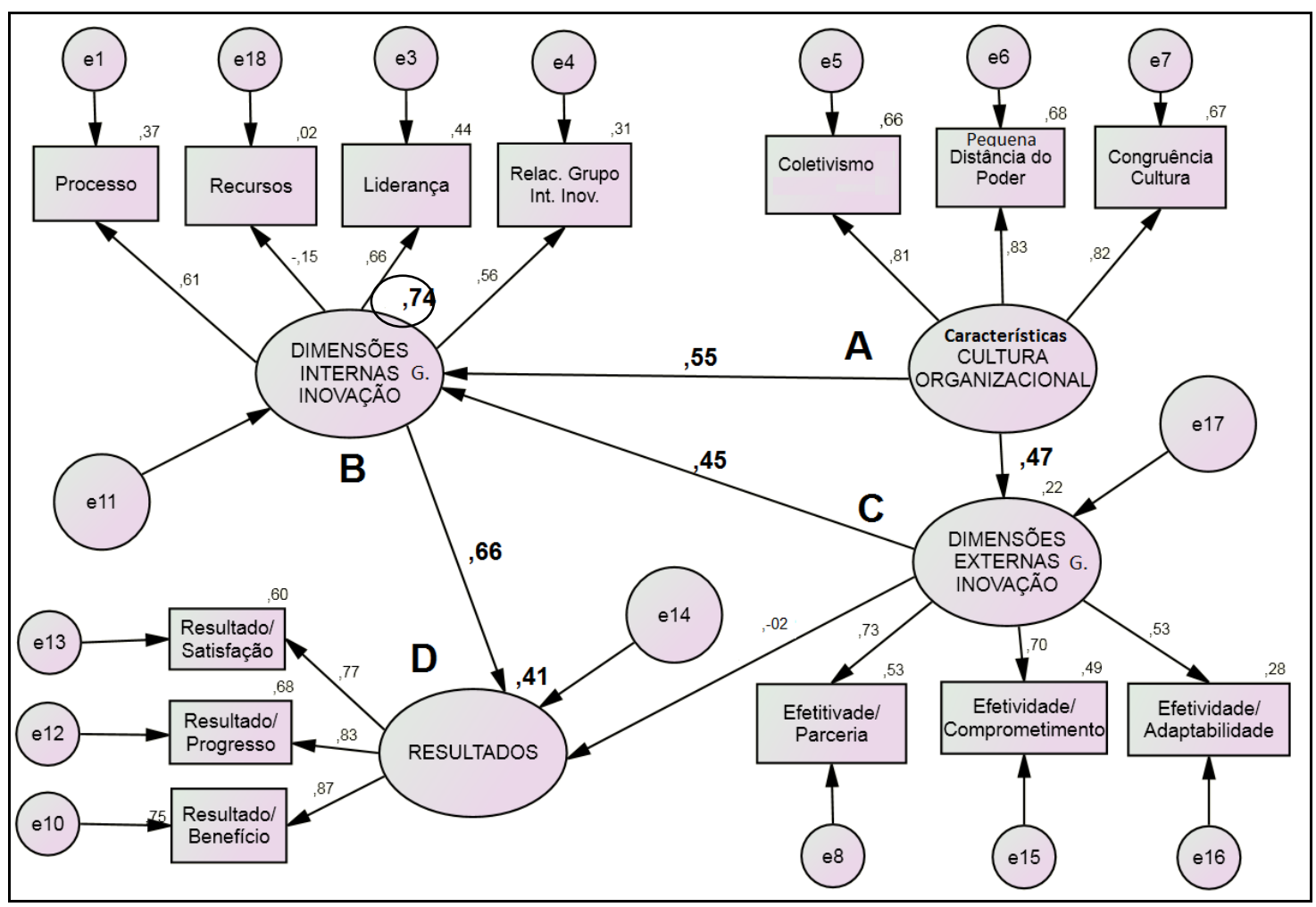

Figura 2 - Diagrama do Modelo - Ambiente Propício ao Desenvolvimento de Inovações Fonte: Dados da pesquisa (todos os coeficientes dos caminhos (pesos beta) são padronizados) 


\subsubsection{H1: A Cultura Organizacional impacta as Dimensões Internas do grupo de Inovação}

Inicialmente será avaliada a influência da Cultura Organizacional (A) sobre as Dimensões Internas do grupo de Inovação (B), conforme a Figura 2, buscando confirmar a primeira hipótese proposta neste estudo. É possível observar também que o construto exógeno Cultura Organizacional (A) é composto pelas dimensões Coletivismo, Pequena Distância do Poder e Congruência Cultural, as quais explicam o construto com coeficientes de $(, 81),(, 83)$ e $(, 82)$, respectivamente. Observa-se que os coeficientes apresentam valores positivos e significativos, demonstrando que os indicadores estão positivamente relacionados com a cultura organizacional. Os coeficientes oferecem informações sobre a extensão em que uma dada variável observável é capaz de medir uma variável latente (Schumacker \& Lomax, 1996). Hair Jr. et al. (2005, p. 490) sugere que esse valor deva exceder 0,50 para que o construto seja considerado verdadeiramente representativo.

Percebe-se que o construto endógeno Dimensões Internas do Grupo de Inovação (B) é representado pelas dimensões Processo em (,61), Recursos em (-,15), Liderança em (,66) e Relacionamento do Grupo Interno à Inovação em (,56).

A dimensão Recursos apresentou-se negativamente ao construto, o que pode estar relacionado à dispersão dos dados apresentados. Mesmo assim, foi uma dimensão percebida pelos empregados, e sua confiabilidade foi garantida com alfa de Cronbach de 0,86, optando-se desta forma por mantê-la no modelo, visto que quando o modelo foi testado sem ela, os resultados permaneceram praticamente iguais, com uma alteração de $1 \%$ de acréscimo em cada variável. Isto pode indicar a não percepção dos recursos por parte dos funcionários.

O impacto do construto Cultura Organizacional sobre as Dimensões Internas do Grupo de Inovação (B) é de (,55). Para Schein (1984), a cultura organizacional acontece por meio de vivências, experiências e realizações, que com o passar do tempo se tornaram a forma certa de fazer as coisas. A empresa estudada possuiu uma forte congruência cultural, voltada para o coletivismo e para uma pequena distância do poder (Bates et al., 1995). Essas características dão aporte às Dimensões Internas do Grupo de Inovação, as quais revelam que as regras são bem definidas e os procedimentos padronizados, inclusive com planejamento estratégico de um ano para outro, em que cada gerência tem conhecimento da disponibilidade de seus recursos. Além disso, a liderança atua de forma incentivadora e presente, tendo visto a proximidade entre os empregados e suas gerências, auxiliando inclusive na sinergia criada pelo grupo para debates e resoluções de conflitos (Van de Ven \& Chu, 1989; Machado, Carvalho \& Heinzmann, 2012). 
Com isso, a hipótese $\mathrm{H} 1$, na qual o construto exógeno Cultura Organizacional impacta positivamente em $(, 55)$ sobre o construto endógeno Dimensões Internas do grupo de Inovação, é aceita.

\subsubsection{H2: A Cultura Organizacional impacta as Dimensões Externas ao grupo de Inovação}

A seguir, pretende-se confirmar a segunda hipótese, a qual afirma que a Cultura Organizacional (A) possui impacto positivo sobre as Dimensões Externas ao grupo de Inovação (C), demonstrado na Figura 2.

O construto Dimensões Externas do grupo de Inovação (C) é representado pela dimensão Efetividade, que por sua vez foi divido em três indicadores - número mínimo indicado por Hair Jr., et al. (2005). A questão Parceria representa a dimensão em (,73), Comprometimento em (,70) e a Adaptabilidade em (,53).

A Cultura organizacional (A) influencia em $(, 47)$ as Dimensões Externas do grupo de Inovação (C), sendo este um construto com poder de explicação sobre o modelo de $(, 22)$.

Com uma cultura congruente que preserva o coletivismo e a menor distância ao poder (Bates et al., 1995), a empresa pesquisada demonstra, pela Figura 2, que os empregados percebem que valem a pena as parcerias firmadas com outros grupos para o desenvolvimento de uma ideia, pois os compromissos assumidos são cumpridos e os objetivos propostos são alcançados (Van de Ven \& Chu, 1989, Machado, Carvalho \& Heinzmann, 2012).

Dessa forma, é possível aceitar a hipótese H2, afirmando haver impacto positivo de $(, 47)$ do construto exógeno Cultura Organizacional sobre o construto endógeno Dimensões Externas ao grupo de Inovação.

\subsubsection{H3: Cultura Organizacional composta com as Dimensões Externas ao grupo de Inovação impactam as Dimensões Internas do grupo de Inovação}

Neste tópico, almeja-se confirmar a terceira hipótese, que afirma haver um resultado positivo para as Dimensões Internas do grupo de Inovação (B) quando esta recebe influência da Cultura Organizacional (A) adicionada às Dimensões Externas ao grupo de Inovação (C), representada na Figura 2.

A relação entre a Cultura Organizacional (A) e as Dimensões Externas de grupo de Inovação (C) possuem um impacto de $(, 45)$ sobre as Dimensões Internas do Grupo de Inovação (B). Essa associação faz com que o construto (B) tenha um poder de explicação do modelo proposto de $(, 74)$.

Revista de Administração e Inovação, São Paulo, v. 12, n.1, p.148-173, jan./mar. 2015. 
A cultura permeia todo o ambiente organizacional. Dessa forma, quando aliada às Dimensões Externas de grupo de Inovação, ela enfatiza a importância atribuída às pessoas. O uso de equipes interdepartamentais fornece subsídios para que o grupo desenvolvedor de uma determinada inovação possa realizá-la com êxito (Moch \& Morse, 1977; Sbragia, 1993; Tidd, Bessant \& Pavitt, 1997; Ahmed, 1998a, 1998b; Kanter et al., 1998; Miguel \& Teixeira 2009). Com isso, o grau de integração dos grupos se reflete na estrutura organizacional e, consequentemente, no ambiente de inovação (Vicenti \& Machado, 2010).

Sendo assim, se aceita a hipótese H3, segundo a qual o construto exógeno Cultura Organizacional, composto pelas Dimensões Externas ao grupo de Inovação, impacta positivamente no construto endógeno Dimensões Internas do grupo de Inovação em (,74).

\subsubsection{H4: A Cultura Organizacional composta com as Dimensões Externas ao grupo de Inovação impacta os Resultados}

Neste item, espera-se verificar a relação positiva da Cultura Organizacional (A) juntamente com as Dimensões Externas (C) ao grupo de Inovação sobre a dimensão Resultados (D).

Conforme apresentado na Figura 2, a dimensão Resultado (D) é composta pelo item Satisfação, que responde por $(, 77)$ do construto, por Progresso, representado $(, 83)$, e por Benefício, com $(, 87)$.

A Cultura Organizacional (A) adicionada às Dimensões Externas ao Grupo de Inovação (C) aparece negativamente relacionada ao construto Resultados (D) em (-,02). Conforme o resultado negativo supõe-se não haver uma relação significativa, não sendo possível fazer conclusões acerca das relações entre estes construtos.

Diante disto, conforme o exposto neste estudo é rejeitada a hipótese H4, que afirma que o construto exógeno Cultura Organizacional, composto com o construto endógeno Dimensões Externas ao grupo de Inovação, impacta no construto Resultados.

\subsubsection{H5: A Cultura Organizacional composta com as Dimensões Internas e Externas ao grupo de Inovação impacta os Resultados}

Por fim, é apresentada a última hipótese, que propõe confirmar que a Cultura Organizacional (A), compartilhada com o grupo Interno (B) e Externo (C) de Inovação, impacta positivamente no construto Resultado (D). O diagrama apresentado na Figura 2 ilustra as relações propostas, bem como a magnitude dos efeitos diretos e indiretos entre as dimensões. As regras da análise de caminhos nos permitem usar as correlações simples entre construtos para estimar as relações causais estabelecidas entre duas variáveis. A causalidade requer que exista um grau suficiente de associação (correlação)

Revista de Administração e Inovação, São Paulo, v.12, n.1, p.148-173, jan./mar. 2015. 
entre as duas varáveis, que uma variável seja claramente o resultado de outra (princípio "causa e efeito").

Os caminhos neste estudo compõem o construto exógeno, representado pela Cultura Organizacional como variável preditora ou independente. E os construtos endógenos, caracterizados pelas Dimensões Internas Inovação, as Dimensões Externas Inovação e os Resultados, como variáveis dependentes.

Com isso, é possível verificar que o construto Cultura Organizacional (A) impacta em $(, 55)$ sobre as Dimensões Internas do grupo de Inovação (B) e em $(, 47)$ as Dimensões Externas do Grupo de Inovação (C).

Aliadas à Cultura Organizacional (A), as Dimensões Externas do Grupo de Inovação (C) influenciam as Dimensões Internas do Grupo de Inovação (B) em $(, 45)$, fazendo com que essa relação consiga explicar as Dimensões Internas do Grupo de Inovação (B) em (,74).

Já o construto Cultura Organizacional (A) unificado às Dimensões Externas do Grupo de Inovação (C) e às Dimensões Internas do Grupo de Inovação (B) influencia o construto Resultado em (,66) e faz com que ele possua um poder de explicação de (,41). Características organizacionais facilitadoras requerem práticas de gestão, integrando os diversos setores em uma única unidade, essa prática resultará em um ambiente mais propício ao desenvolvimento de inovações, pois a inovação requer altos níveis de trabalho em equipe interfuncional e interorganizacional (Tidd, Bessant \& Pavitt, 1997; Kanter et al., 1998; Parolin \& Albuquerque, 2010).

Dessa forma, é possível aceitar neste estudo a hipótese H5, que afirma que a Cultura Organizacional, composta com as Dimensões Internas e Externas ao grupo de Inovação, impacta sobre Resultados.

\subsection{Diagrama de caminhos de ambiente propício ao desenvolvimento de inovações sem o construto 'cultura organizacional'}

Quando calculado o modelo sem o construto 'cultura organizacional', o modelo apresenta bons índices de ajustes, porém, o impacto das Dimensões Externas ao Grupo de inovação sobre as Dimensões Internas ao grupo de Inovação cai para $(46), 28 \%$ menor quando comparadas ao modelo com o construto Cultura, que é de (,74).

Conclui-se, portanto, que o construto Cultura Organizacional possui uma influência positiva sobre o desenvolvimento de um ambiente propício ao desenvolvimento de inovações, pois o ambiente 
organizacional é permeado por uma cultura, que mesmo intangível, possui influência nos processos de manutenção e promoção da inovação organizacional.

Alguns autores relatam que organizações inovadoras possuem certas características culturais distintas das demais, tais como a liderança institucional voltada para o fomento de novas ideias e o comprometimento dos empregados para com a inovação, além de aspectos como autonomia, criatividade e descentralização, entre outros (Martins \& Terblanche, 2003; Ahmed, 1998a, b; Parolin \& Albuquerque, 2010). Além disso, a ausência de uma cultura voltada para a inovação afeta a dimensão em que soluções criativas são estimuladas para a resolução de problemas (Martins \& Terblanche, 2003).

Assim sendo, uma empresa com uma cultura inovativa é proativa no desenvolvimento de inovações, estimulando todos os empregados a participarem do processo, sem restringir a atividade a um único setor. Ao mesmo tempo, fornece suporte à inovação com práticas gerenciais que promovem a geração de ideias e a execução de novos projetos (Gobara et al., 2010).

\section{CONSIDERAÇÕES FINAIS}

A cultura organizacional, nesta pesquisa, foi avaliada como algo que a empresa "tem", encarado como um componente de gestão passível de gerenciamento e tratamento, podendo ser estudada como uma variável interna, com a finalidade de apoiar as decisões da alta administração no que se refere a informações claras, objetivas e racionais. Assim, partiu-se do paradigma funcionalista positivista para desenvolver a análise. Neste sentido, este estudo teve como objetivo geral analisar o impacto da cultura organizacional sobre o ambiente propício ao desenvolvimento de inovações em uma empresa do setor metal-mecânico.

O modelo proposto se mostrou aderente, pois quatro das cinco hipóteses foram confirmadas, indicando que a empresa pesquisada possuiu uma cultura organizacional que favorece um ambiente propício à inovação.

Com isso, é possível inferir que na empresa pesquisada existe contato entre a produção e os gerentes de fábrica, supervisores, engenheiros e profissionais técnicos, diminuindo assim a distância do poder entre as partes e permitindo maior coletividade entre os empregados, gerando liberdade e segurança para a tomada de decisão. Diante do exposto, confirma-se que a empresa é possuidora de uma congruência cultural, o que significa dizer que os seus empregados possuem valores culturais similares e compartilham crenças e objetivos comuns.

Revista de Administração e Inovação, São Paulo, v.12, n.1, p.148-173, jan./mar. 2015. 
Ainda é possível dizer que os empregados percebem que as regras e os procedimentos são bem definidos quando do desenvolvimento de uma ideia, que existe uma liderança incentivadora e um bom relacionamento entre a equipe de trabalho. Que as parcerias firmadas com outros grupos para o desenvolvimento de uma ideia valem a pena, pois os compromissos assumidos são cumpridos e os objetivos propostos são alcançados, mesmo que esse apoio não seja percebido na esfera financeira.

Entretanto, também foi demonstrado que os empregados percebem a inovação como consequência da efetividade do grupo interno e não do grupo externo a ela, e ainda que este participe ativamente no desenvolvimento da inovação, o resultado final é creditado ao grupo desenvolvedor.

Para o campo científico, espera-se que o presente estudo contribua para o entendimento das relações entre as variáveis "cultura organizacional" e "ambiente propício a inovações". Apesar de constituírem campos epistemológicos diversos, a conjunção dos objetos de estudo se mostrou factível e demonstrou uma faceta pouco explorada na academia. Em decorrência disso, também se espera contribuir para as pesquisas quantitativas sobre cultura, abordagem essa ainda pouco utilizada no meio acadêmico no Brasil.

Como contribuição prática para a empresa pesquisada, pode-se demonstrar que a forte congruência cultural, aliada à pequena distância do poder e alto coletivismo, faz com que o processo de inovação ocorra de forma efetiva, por haver equipes de trabalho comprometidas com seu desenvolvimento. Contudo, os resultados evidenciaram que é importante um trabalho de integração entre equipes, que é preciso uma melhor divulgação dos recursos disponíveis e que o processo de inovação necessita de uma formalização para que as informações se tornem acessíveis a todos os empregados.

Recomenda-se desenvolver outros estudos exploratórios como este, concentrados no setor metal-mecânico. A partir desse setor, estender às demais áreas industriais, para possíveis comparações e para a formação de um panorama mais completo sobre ambientes propícios ao desenvolvimento de inovações. Como limitação deste estudo está o corte transversal e a aplicação desta pesquisa a um único objeto de estudo, não sendo passível de generalizações. 


\section{REFERÊNCIAS}

Afuah, A. (2003). Innovation management: strategies, implementation and profits. New York: Oxford University Press.

Aiken, M., \& Hage, J. (1966). Organizational Alienation: A Comparative Analysis. American Sociological Review, 31, 497-507.

Aiman-Smith, L. (2004). What do we know about developing and sustaining a culture of innovation. What do we Know Journal Review, 1(5).

Ahmed, P. K. (1998a). Culture and climate for innovation. European Journal of Innovation Management, 1(1), 30-43.

(1998b). Benchmarking innovation best practice. European Centre of Total Quality Management, 5(1), 45-58.

Anderson, J. C., \& Gerbing, D. W. (1988). Structural equation modeling in practice: a review and recommended two-step approach. Psychological Bulletin, 103(3), 411-423.

Anderson, D. R., Sweeney, D. J., Williams, T. A. (2011). Estatística Aplicada à Administração e Economia. São Paulo: Cengage Learning.

Barbetta, P. A. (2001). Estatística aplicada às ciências sociais. Florianópolis: Ed. UFSC.

Bates, K. A., Amundson, S. D., Schroeder, R. G., \& Morris, W. T. (1995). The Crucial Interrelationship between Manufacturing Strategy and Organizational Culture. Management Science, 41(10), 1565-1580, oct.

Bentler, P. M. (1988). Causal modeling via structural equation systems. In: Nesselroade, J. R. \& Cattell, R. B. (Eds.). Handbook of multivariate experimental psychology (2nd ed., p. 317-335). New York: Plenum.

Burrel, G., \& Morgan, G. (1979). Sociological paradigms and organizational analysis. Londres: Heinemann.

Börjesson, S., Elmquist, M. (2011). Developing Innovation Capabilities: A Longitudinal Study of a Project at Volvo Cars. Creativity and Innovation Management, 20(3), 171-184.

Damanpour, F. (1991). Organizational innovation: a meta-analysis of effects of determinants and moderators. Academy of Management Journal, 34(3), 555-590.

Dosi, G. (1982). Technological paradigms and technological trajectories. Research Policy, 11(2), 147162.

(1988). Sources, procedures and microeconomic effects of innovation. Journal of Economic Literature, 26(3), 1120-1171.

Downs , G. W., \& Mohr Jr., L. B. (1976). Conceptual Issues in the Study of Innovation. Administrative Science Quarterly, 21(4), 700-714, dec.

Georgopoulos, B. S., \& Mann, F. C. (1962). The community general hospital. MacMillan: New York.

Revista de Administração e Inovação, São Paulo, v.12, n.1, p.148-173, jan./mar. 2015. 
Gregory, B. T., Harris, S. G., Armenakis, A. A., \& Shook, C. L. (2009). Organizational culture and effectiveness: A study of values, attitudes, and organizational outcomes. Journal of Business Research, $62,673-679$.

Gobara, C., Rossoni, L., Kato, E. M., \& Hocayen-da-Silva; A. J. (2010). A influência das dimensões da cultura organizacional na inovação em serviços: uma análise do setor hoteleiro. Revista de Administração e Contabilidade da Unisinos, 7(4).

Goh, K. T., Goodman, P. S., \& Weingart, L. R. (2013). Team Innovation Processes An Examination of Activity Cycles in Creative Project Teams. Small Group Research, 44(2), 159-194.

Gundling, E. (1999). The 3M Way to innovation: balancing people and profit. New York: Vintage Books.

Efrat, K. The direct and indirect impact of culture on innovation. (2014). Technovation, 34, 12-20.

Hair Jr., J. F., Babin, B., Money, A. H., \& Samouel, P. (2005). Fundamentos e métodos de pesquisa em administração. Porto Alegre: Bookman.

Hall, R. H. (1984). Organizações: estrutura e processos. 3. ed. Rio de Janeiro: Prentice/Hall do Brasil, 260p.

Hamel, G. (2006). Alta Gerência: o laboratório de inovação em gestão. Revista HSM Management. São Paulo, edição 58. Disponível em: < http://www.hsm.com.br/revista/alta-gerencia-o-laboratorio-deinovacao-em-gestao>. Acesso em: 21 de junho de 2012.

Hatch, M. J. (1997). Organization theory: modern symbolic and postmodern perspectives. New York: Oxford University Press.

Hofstede, G. (1980). Culture's Consequences: international differences in work related values. Beverly Hills: Sage.

Hogan, S. J., Coote, L. V. (2014). Organizational culture, innovation, and performance: A test of Schein's model. Journal of Business Research, 67, 1609-1621.

Howard, L. W. (1998). Validating the competing values model as a representation of organizational cultures. The International Journal of Organizational Analysis, 6(3), 231-25.

Hurley, R. F., \& Hult, G. T. M. (1998). Innovation, market orientation and organizational learning: an integration and empirical examination. Journal of Marketing, 62, 42-54, jul.

Ismail, W., \& Abdmajid, R. (2007). Framework of the culture of innovation: a revisit. Journal Kemanusiaan , 9, 38-49.

Kannan-Narasimhan, R. (2014). Organizational Ingenuity in Nascent Innovations: Gaining Resources and Legitimacy through Unconventional Actions. Organization Studies, 35(4), 483-509.

Kanter, R. M., Kao, J. J., \& Wiersema, F. D. (1998). Inovação: pensamento inovador na 3M, DuPont, GE, Pfizer e Rubbermaid. São Paulo: Negócio, 194 p.

Kline, R. B. (1998). Principles and practice of structural equation modeling. New York: The Guilford Press, 354p. 
Machado, D. D. P. N. (2007). Organizações Inovadoras: Estudo dos fatores que formam um ambiente inovador. Revista de Administração e Inovação, v. 4, p. 1-35.

; Carvalho, L. C.; Heinzmann, L. M. (2012). Ambiente Favorável ao desenvolvimento de inovações: integração de duas perspectivas de análise. Revista de Administração da Universidade de São Paulo-RAUSP, 47(4), 715-729, out./nov./dez.

\& Carvalho, L. C. (2013). Ambiente favorável ao desenvolvimento de inovações: proposição de um modelo de análise organizacional. Revista de Administração (FEA-USP), 48, 592-607.

Martins, E. C.;Terblanche, F. (2003). Building organisational culture that stimulates creativity and innovation. European Journal of Innovation Management, 6(1), 64-74.

Miguel, L. A. P., \& Teixeira, M. L. M. (2009). Valores Organizacionais e Criação do Conhecimento Organizacional Inovador. Revista de. Administração Contemporânea - RAC, 13(1), 36-56, jan./mar.

Moch, M. K., \& Morse, E. V. (1977). Size, Centralization, and Organizational Adoption of Innovation. American Sociological Review, 42(5), 716-25, oct.

Moran, T. J., \& Meso, P. (2008). A resource based view of manufacturing strategy and implications to organizational culture and human resources. Journal of Business \& Economics Research, 6(11), 99109.

Mueller, V., Rosenbusch, N., \& A. Bausch. (2013). Success Patterns of Exploratory and Exploitative Innovation: A Meta-Analysis of the Influence of Institutional Factors. Journal of Management, 39(6), 1606-1636.

Naor, M., Linderman, K., \& Schroeder, R. (2010). The globalization of operations in Eastern and Western countries: unpacking the relationship between national and organizational culture and its impact on manufacturing performance. Journal of Operations Management, 28, 194-205.

Ouchi, W. G. (1979). A conceptual framework for the design of organizational control mechanisms. Management Science, 25(9), 833-848.

. (1982). Teoria Z: como as empresas podem enfrentar o desafio japonês. São Paulo: Ed.

Fundo Educativo Brasileiro.

O'leary-Kelly, S. W., \& Vokurka, R. J. (1998). The empirical assessment of construct validity. Journalof Operations Management, 16(4), 387-405.

Parolin, S. R. H., \& Albuquerque, L. G. (2010). Gestão de pessoas para a criatividade em organizações inovativas. Revista Eletrônica de Administração - REAd, 16(3), set./dez.

Rogers, E. M., \& Shoemaker, F. F. (1971). Communication of innovations. New York: Free Press.

Rogers, E. (1995). The diffusion of innovation. New York. Free Press.

Saffold, G. S. (1988). Culture Traits, Strength, and Organizational Performance: Moving Beyond 'Strong' Culture. Academy of Management Review, 13(4), 546-558.

Sbragia, R. (1993). Trabalhos em equipe e inovação tecnológica. Revista de Administração, São Paulo - RAUSP, 28(1), 36-43. 
Schein, E. H. (1984). Coming to a New Awareness of Organizational Culture. Sloan Management Review, 25(2), 3-16.

Schultz, M. (1994). On studying organizational cultures: Diagnosis and understanding. Berlin: Walter de Gruyter.

Schumacker, R. E., \& Lomax, R. G. (1996). A beginner's guide to structural equation modeling. New Jersey, Lawrence Erlbaum, 286p.

Schumpeter, J. A. (1911). Theorie der wirtschaftlichen Entwicklung. Leipzig: Duncker und Humblot.

. (1982). Teoria do desenvolvimento econômico: uma investigação sobre lucros, capital, crédito, juro e o ciclo econômico. São Paulo: Abril Cultural, 169 p.

Smircich, L. (1983). Concepts of culture and organizational analysis. Administrative Science Quarterly, 28(3), p. 339-358, set.

Taylor, J. C., \& Bowers, D. B. (1972). Survey of Organizations: A Machine Scored Standardized Questionnaire Instrument. Institute for Social Research, University of Michigan: Ann Arbor, MI,

Tidd, J., Bessant, J., \& Pavitt, K. (1997). Managing innovation: integrating technological, market and organizational change. Chichester: John Wiley and Sons.

Van de Ven, A. H. (1986). Central problems in the management of innovation. Management Science, 32(5), 590-607.

, Chu, Y. (1989). A psychometric assessment of the Minnesota innovation survey Chapter 3. In:___ ANGLE, H.; POOLE, M. S. (Org.). Research on the management of innovation: the minnesota studies. New York: Oxford University.

; Angle, H. L. (1989). An introduction to the Minnesota innovation research program. In: .; ___ POOLE, M. S. (Org.). Research on the management of innovation. New York: Ballinger/Harper \& Row, p. 3-30.

Vicenti, T., \& Machado, D. D. P. N. (2010). Ambiente de inovação em empresas de software: estudo das diferenças entre empresa-mãe e seus spin offs. Revista Eletrônica de Administração - REAd, 16(1), jan.-abr.

Vick, T., Nagano, M. S., \& Santos, F. C. (2009). A. Aportes da gestão da informação para a criação de conhecimento em equipes de inovação. Perspectivas em Ciência da Informação, 14(2), 204-219, maio/ago.

Wolfe, R. A. (1994). Organizational innovation: review, critique and suggested research directions. Journal of Management Studies, 31, 405- 43.

Yang, D., \& Yang, J. (2012). The match between efficiency/flexibility strategy and organisational culture. International Journal of Production Research, 50(19), 5317-5329.

Zaltman, G., Duncan, R., \& Holbeck, J. (1973). Innovations and Organizations. New York: Wiley Interscience.

Revista de Administração e Inovação, São Paulo, v. 12, n.1, p.148-173, jan./mar. 2015. 


\title{
THE IMPACT OF CULTURE ON ENABLING ENVIRONMENT FOR INNOVATIONS DEVELOPMENT
}

\begin{abstract}
The aim of this study is to analyze the impact of organizational culture on enabling environment for innovation development in a company's metal-mechanic sector. Therefore a survey was conducted quantitative descriptive cross. The sample is composed of 156 respondents, and the data were analyzed using structural equation modeling. As main result, employees of the company studied the dimensions highlighted Results, Processes, Resources, Leadership, Internal Relationship Group for Innovation and Effectiveness Relationship as present in the environment conducive to innovation. An organizational culture congruent with small power distance and high collectivism.
\end{abstract}

Keywords: Innovation; Organizational Culture; Environment; Structural Equation.

Data do recebimento do artigo: 25/03/2014

Data do aceite de publicação: 04/03/2015

Revista de Administração e Inovação, São Paulo, v.12, n.1, p.148-173, jan./mar. 2015. 